\title{
Research on Precision Marketing of University Teaching Materials in Big Data Era
}

\author{
Yang Chunji ${ }^{1,2, *}$, Wei Yuanzhu ${ }^{1}$ \\ ${ }^{1}$ School of Management, Fujian Agriculture and Forestry University,China \\ ${ }^{2}$ School of Business, GanNan Normal University,China \\ *yangchunjiyang@163.com
}

\begin{abstract}
The marketing environment of university teaching materials has undergone great changes, facing many challenges. Big data provides an important opportunity for marketing of university teaching materials. This paper analyzes the impact of big data on marketing environment of university teaching materials and studies the precise marketing mode of university teaching materials in the big data environment, etc. with a view to helping publishers.
\end{abstract}

Keywords: big data; marketing materials; precision marketing

\section{Introduction}

Over the past 40 years since resumption of college entrance examination, especially after college enrollment expansion in 1999, China's higher education has achieved remarkable achievements. With the rapid development of information technology, market competition of university teaching materials is becoming more and more intense. How to meet the needs of the times, meet the needs of university teaching materials, and solve the difficulties faced by material marketing is a challenge for publishers. Big date provides a solving idea for marketing of university teaching materials.

Since 2008, big data has aroused great concern of news media, academia and the business community. Value of big data is an important driving factor that enhances China's future innovation and competitiveness. In 2008, famous journal "Nature" published big data special issue which introduced opportunities and challenges brought by big data from the perspectives of Internet economy, supercomputer, etc. In the same year, three professors from Carnegie Mellon University, University of California at Berkeley and University of Washington jointly published big data computing white paper which explained challenges of big data to technology, business and society and coping technology. McKinsey's big data research report in 2011 made a deep analysis of social value of big data. 2012 saw energetic development of big data. Firstly, World Economic Forum published report "big data, big impact", announcing that big data has become an important tool for economic and social development. Immediately, New York Times published article "the age of big data" which pointed out that big data-driven decision-making research has been applied in the fields of economy, health and social networks. Afterwards, the US government invested \$200 million to launch big data research program, and publication of "Big Data" by Viktor Mayer-Schnberger and Kenneth Cukier promoted popularization of big data.

Domestic scholars also immediately started big data research. Wei Yingjie (2014) analyzed publication of academic writings in big data era from the perspectives of topic planning, editing and publishing and marketing. Wang Dong (2014) analyzed Map-Reduce, NoSQL and Key-Value and proposed big data-based solutions for precision marketing. Leng Qiaoxun and Li Keming (2016) analyzed from the perspective of transition of traditional publishing enterprises in big data era, and put forward that traditional publishers must pay attention to big data application so as to improve competitiveness. In 2014, Premier Li Keqiang first mentioned big data in "Government Work Report". On August 31, 2015, release of the National Document "Action Program on Promoting Development of Big Data" marked the 
unprecedented opportunity for China's big data construction. Nevertheless, there is rare paper analyzing precision marketing of university teaching materials from the perspective of big data, which is a question worthy of study.

\section{Analysis on change of marketing environment of university teaching materials in China}

China's teaching material publishing and marketing environment is subjected to multiple factors of national policy, market environment and technical environment.

First, university teaching materials are different from ordinary books in that they are affected by national and local government policies, rules and regulations. For instance, documents promulgated by the state such as "Decision on Deepening Education Reform, Comprehensively Promoting Quality-Oriented Education", "Teaching Quality and Teaching Reform Project in Higher Institutions", "Eleventh Five-Year Planning Teaching Materials for General Higher Education" and "Some Opinions on the 12th Five Year Undergraduate Teaching Material Construction in General Higher Education" will exert an important impact on our universities. Moreover, with the transformation of higher education from scale to quality, the masses hold higher expectations for education and teaching methods, quality of personnel training, which will directly and indirectly affect preparation and publication of teaching materials.

Second, China's university teaching material market has been gradually marketized from the early state control, publishers have also completed transition and restructuring in 2011. The continuous market expansion of university teaching material with high profits and stable consumer groups has attracted many publishers to join the competition in publishing university teaching materials, triggering increasingly fierce competition.

Finally, with the rapid development of Internet technology, many new features emerged in use of university teaching materials. For instance, recycling, copy of teaching materials, electronic paper books and digital technology, etc. have caused a greater impact on publishing of traditional teaching materials, and even changed university education and teaching environment, which troubles publishers. How to adapt to the new media environment and cater to changes in consumers affects publishers' traditional marketing methods for teaching materials.

\section{Impact of big data on precision marketing of teaching materials}

In 1999, American marketing scientist Lester Wunderman proposed the concept of precision marketing. He believed that precision marketing is a marketing model that has accurate access to consumer and market information by virtue of information technology, and then establishes interactive communication between the two sides to gain competitive advantage and high returns. With the use of big data technology, precision marketing gains favor with remarkable results. For example, Amazon's book recommendation system is a model of precision marketing.

Precision marketing can only be realized with the help of big data. Leveraging big data platform built by publishers, related data about books, authors, teachers, students, related readers and competitors can be collected, stored and excavated. On this basis, it helps publishers analyze and predict teaching material market, formulate personalized marketing programs based on the prediction results to guide marketing activities, specifically demonstrated in the following aspects:

\subsection{Precision of topic selection}

Quality of teaching materials depends largely on topic selection, and precision of book selection can be achieved in big data environment. Via big data platform, publishers can collect teaching material usage information of university teachers and students in the past years, investigate their satisfaction in teaching 
material usage, and follow the feedback information. Through the analysis and excavation of behavior and preferences of general teachers and students, it is even possible that teachers and students can participate in the selection process, making the topic selection more targeted and open.

\subsection{Precision of content production}

Production of teaching material contents should take consumers (teachers and students) as the center, improvement in education and teaching quality as the basis, and achieve precision by leveraging big data. Thanks to the big data platform built by publishers, in addition to precise selection of topics, there is mass data available for selection of teaching material contents. Moreover, university teachers and students can participate in the whole content production process, so that high quality teaching materials can be produced by processing content system, text style, arrangement style of teaching materials.

\subsection{Precision of marketing promotion}

In the teaching material marketing stage, precision is possible via big data. With publishers' big data platform, precise book promotion and publicity is possible based on users' features of preferences, feedback information, university type, professional level, etc.

\section{Analysis of precision marketing model of teaching materials based on big data}

In this study, we combine classic 4P (product, place, price, promotion) and 4C (consumer, cost, convenience and communication) theory, choose four factors of consumers, products, purchasing behavior and value-added services to build precision marketing model in big data environment, as shown in Figure 1. Wherein, consumer mainly refers to university teachers and students, product is mainly publishers' books and derivatives, purchase behavior refers to browsing, collection, message and payment of publishers' products by university teachers and students, and value-added service is mainly book distribution, changing or refunding, etc.

\section{Data Sources}

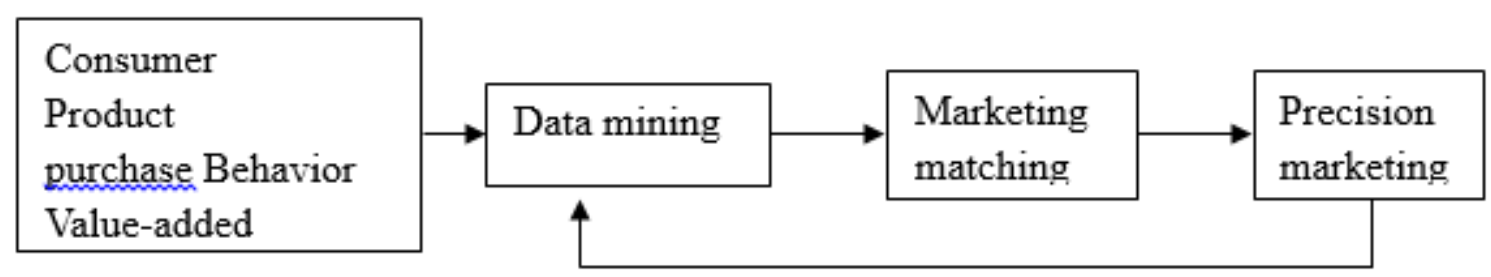

Figure1 precision marketing model

\subsection{Build a publisher big data information system}

In the big data environment, higher competitiveness of university publishers is based on construction of perfect publisher information system through which, internal and external coordination of publishers, efficient and professional operating system can be achieved. Although most publishers have built their own information systems and realized basic website operation, this only realizes internal management of publishers. Publishers are still in the "information island" state, and it is impossible to achieve smooth flow of information in the entire publishing industry chain.

Data represents the core resources of publishers. Precision marketing is impossible without rich resources. Publishers' main resources consist of university resources, product resources and customer resources. Wherein, university resources mainly include school type, secondary schools, professional composition, courses, student scale, professional person in charge, etc.; product resources mainly include publishers' teaching materials and other products, especially competitors' product information, such as textbook name, author, course content, price, award, supporting courseware, graphic design, etc.; customers mainly include teachers, students and agents, wholesalers and retailers, etc.. Based on resource library, marketing 
staff can accurately locate consumers, analyze and compare advantages and disadvantages of products, and develop precision marketing strategy.

Therefore, only with big data system platform, publishers can analyze consumer data, formulate decision-making, and achieve rapid search, recommendation, advertising and logistics support via publishing system platform, making business value.

\subsection{Focus on interaction with consumers}

In the big data era, with the support of publishing system platform, it is easier to realize consumer segmentation. With diversified data mining and statistical analysis tools to thoroughly analyze the collected consumer data, "user portrait" can be outlined. On this basis, products can be segmented from basic characteristics, behavior and psychological characteristics of consumers, and good customer relationship can be established by comprehensive use of integrated marketing communication (IMC) such as advertising, promotion, training, meetings. With the help of new media, such as WeChat, virtual community, microblogging, e-mail, etc. to achieve a good interaction between publishers and consumers, consumers have sufficient opportunity to participate in publishers' topic planning, and publishers can create a good experience environment and strive to provide personalized publishing services.

\subsection{Achieve product differentiation}

Publishers' products for universities are mainly teaching materials. Publishers face double competition pressure. On the one hand, there is a high degree of homogenization in teaching materials published by domestic publishers, lacking obvious differences in quality and function of teaching material products. On the other hand, with the development of information technology, traditional "teaching materials + counseling book" model cannot meet the needs of teachers and students. Therefore, "three-dimensional + value-added services" model should be the development direction for differentiation in teaching materials. Publishers should develop corresponding teaching materials according to different regions, different school levels and different positioning of universities, to achieve differentiated supply.

\subsection{Focus on purchase behavior}

Using publisher big data system, collected consumer (teachers and students, etc.) data can be analyzed, and consumers' basic consumption characteristics can be determined, such as demand preferences, value attitudes, etc., which will affect consumers' purchase willingness and satisfaction. By virtue of big data, publishers can accurately analyze situation of consumers and competitors, tap the data value, and develop scientific marketing mode, to achieve precision marketing, reduce fees and marketing costs.

\subsection{Expand value-added services}

Value-added services mainly involve two aspects. The first is product value-added service, and the second is value-added service chain extension. The so-called product value-added service means value-added business development centering teaching materials. For instance, most publishers only provide "teaching materials + counseling book". On this basis, scope of services can be expanded to provide teaching materials e-books, exquisite courseware and related supplementary data. The so-called value-added service chain extension means continuous extension of service contents based on product value-added services, such as e-book service extension, online education service provision and extension, APP applications, digital publishing, book e-commerce and logistics in line with the current needs. Only by seizing the new situation of reform and development of higher education and clearly judging new problems in the development of higher education can we innovate the model of "production (topic selection) - supply (publishing) - marketing (sale)" of university teaching materials, focus on core business, expand value-added services, construct business model suitable for publishers, maintain publishers' sustainable development and enhance competitiveness. 


\section{Research conclusions}

Big data has great influence on publishers' marketing of teaching materials. This study constructs the precision marketing mode based on big data for university teaching materials from the four aspects of consumers, products, purchasing behavior and value-added services, in a view to helping enhance publishers' competitiveness.

\section{References}

[1]Big data[EB/OL].http://www.nature.com/news/specials/bigdata/index.html,2008

[2]Bryant RE,Katz RH,Lazowska ED. Big data computing: Creating revolutionary breakthroughs in commerce,science and society[R/OL].http://www.cra.org/ccc/files/docs/init/BigData.pdf,2008.

[3]Manyika J,Chui M,Brown B. Big data: The next frontier for innovation, competition and productivity[R/OL].McKinsey Global Institute,2011:1-137.

[4]World Economic Forum. Big data, big impact: New possibilities for international development[EB/OL].http://www3.weforum.org/docs/WEF_TC_MFS_BigDataBigImpact_Briefing 2012.pdf,2012.

[5]Obama administration unveils "Big Data" initiative: Announces \$200 million in new R\&D investments[EB/OL].http://www.whitehouse.gov/sites/default/files/microsites/ostp/big_data_press_re lease_final_2.pdf,2012.

[6]Lohr S. The age of big data[EB/OL].[2014-01-20].

http://www.nytimes.com/2012/02/12/sundayreview/big-datas-impact-in-the-world.html? pagewanted $=$ all,2012

[7] Wei Yingjie. A brief talk on publication of academic journals in big data era [J], View on publishing, $2014(5)$

[8] Su Haoxuan, Ouyang Peng. Study on big data- driven book publishing \& marketing model [J], View on publishing, 2015 (10).

[9] Leng Qiaoxun, Li Keming. Exploration into transformation of traditional publishers in big data era $[\mathrm{J}]$, View on publishing, 2016 (1)

[10] Wang Dong. Application of big data technology in precision marketing, China Business and Market, $2014(7)$ 